\title{
O "TRABALHO LIVRE” E A LEI GERAL DE ACUMULAÇÃO CAPITALISTA: a formação de uma população supérflua para o capital
}

\section{"Free work" and the general law of capitalist accumulation: the formation of a population superfluous to capital}

Aline de Araújo Martins ${ }^{1}$ Eduardo F. Chagas (UFC) ${ }^{2}$

RESUMO: Este artigo visa analisar a lei geral da acumulação capitalista, expressa no fato de a produção da riqueza social implicar na produção contínua da pobreza, uma vez que a riqueza socialmente produzida é apropriada de forma privada. A partir dessa lei tem-se como consequência tanto o desemprego como o pauperismo, a partir da formação de uma população supérflua para o capital. Para isso, traz uma explanação teórica sobre o trabalho, enfatizando que, na sociabilidade capitalista, todas as funções reprodutivas sociais, inclusive o trabalho, são subordinadas ao capital.

Palavras-chaves: Trabalho. Capital. Lei Geral de Acumulação Capitalista.

ABSTRACT: This article aims to analyze the general law of capitalist accumulation, expressed in the fact that the production of social wealth implies in the continuous production of poverty, since the socially produced wealth is appropriated privately. From this law we have as a consequence both unemployment and pauperism, from the formation of a population superfluous to capital. To this end, it provides a theoretical explanation of the work, emphasizing that, in capitalist sociability, all social reproductive functions, including labor, are subordinated to capital.

Keywords: Work. Capital. General Law of Capitalist Accumulation.

\section{INTRODUÇÃO}

O trabalho, a partir da perspectiva marxista, é a categoria fundante do ser social, uma vez que é por meio dele que o homem satisfaz suas necessidades e amplia suas possibilidades de sobrevivência. Assim, por meio do trabalho o homem

\footnotetext{
${ }^{1}$ Assistente Social. Mestre em Serviço Social, Trabalho e Questão Social pela Universidade Estadual do Ceará - UECE. Professora do curso de Serviço Social da Faculdade Ratio. E-mail: alinemartinss@hotmail.com

${ }^{2}$ Doutor em Filosofia pela Universidade de Kassel, Alemanha. Professor Associado IV da Graduação e Pós-Graduação do Curso de Filosofia da Universidade Federal do Ceará (UFC) e Colaborador do Programa de Pós-Graduação em Educação Brasileira da Faculdade de Educação da Universidade Federal do Ceará (FACED/UFC). Bolsista do CNPq. E-mail: ef.chagas@uol.com.br
} 
desenvolve suas habilidades, modifica 0 meio sobre 0 qual vive $e$, consequentemente, modifica a si mesmo. Foi o trabalho que possibilitou ao homem romper com a esfera meramente biológica, constituindo-se como ser social.

Porém, o sistema sociometabólico do capital (MESZÁROS, 2011) ao subordinar o trabalho às suas funções, torna-o alienado e alienante, uma vez que seus resultados não pertencem mais àqueles que os produzem, mas ao capitalista, detentor dos meios de produção. Este, ao obter lucros, incorpora no processo produtivo avanços técnicos e científicos e diminui o tempo de trabalho socialmente necessário, ao subordinar o trabalho vivo (trabalho concreto) ao trabalho morto (trabalho abstrato), ocasionando exploração e reprodução do capital, bem como o fenômeno do pauperismo e do desemprego. Portanto, o desemprego é estrutural à sociedade capitalista, que, ao produzir riqueza, produz concomitantemente uma população supérflua às necessidades do capital.

\section{O TRABALHO SOB O SISTEMA SOCIOMETABÓLICO DO CAPITAL}

O trabalho, independentemente de qualquer forma de sociedade, é uma condição básica para a sobrevivência humana na terra. Trata-se da atividade pela qual o homem, desde seus primórdios, atua sobre a natureza a fim de satisfazer suas necessidades, desenvolvendo, assim, suas capacidades, ampliando seus conhecimentos e adquirindo novas habilidades. Desse modo, na medida em que o homem modifica o meio em que vive, a partir de sua capacidade física e teleológica, também modifica a si mesmo.

Nessa perspectiva, Marx (2004, p. 211) define o trabalho como:

Um processo de que participam o homem e a natureza, processo em que o ser humano, com sua própria ação, impulsiona, regula e controla seu intercâmbio material com a natureza. Defronta-se com a natureza como uma de suas forças. Põe em movimento as forças naturais de seu corpo - braços e pernas, cabeça e mãos -, a fim de apropriar-se dos recursos da natureza externa e modificando-a, ao mesmo tempo modifica a sua própria natureza. Desenvolve as potencialidades nela adormecidas e submete ao seu domínio o jogo das forças naturais. 
$\mathrm{Na}$ concepção marxiana, o trabalho funda o ser social e assume a centralidade na sociabilidade humana, diferenciando o homem dos animais, uma vez que somente o primeiro tem a capacidade de antecipar em sua mente o resultado de suas ações, antes mesmo de realizá-las. Tal capacidade, denominada por Lukács (1968) de teleologia, é explicitada na seguinte comparação de Marx:

Uma aranha executa operações semelhantes às do tecelão, e a abelha supera mais de um arquiteto ao construir sua colmeia. Mas o que distingue o pior arquiteto da melhor abelha é que ele figura na sua mente sua construção antes de transformá-la em realidade. No fim do processo do trabalho aparece um resultado que já existia antes idealmente na imaginação do trabalhador. Ele não transforma apenas o material sobre o qual opera; ele imprime ao material 0 projeto que tinha conscientemente em mira (...) (MARX, 2004, p. 211212).

O trabalho é, portanto, a categoria que permite o salto ontológico ${ }^{3}$ do ser puramente biológico ao ser social. Em outras palavras, o salto não se dá a partir da mera fabricação de produtos, mas através do papel desempenhado pela consciência, capaz de ultrapassar o mero epifenômeno da reprodução biológica (LUKÁCS, 1968).

Lessa (2007) observa que é somente no século XIX, a partir das contribuições de Marx, que a história passa a ser compreendida como resultado exclusivo da ação dos homens em sociedade, a qual está fundada no trabalho. Segundo o autor,
É preciso notar que, para Marx, o fato de o trabalho ser a categoria fundante do mundo dos homens não significa que o trabalho seja a ele anterior, nem significa que não possa ser modificado pela história que ele próprio funda. Muito pelo contrário, para o pensador alemão o trabalho apenas pode ser categoria fundante do mundo dos homens porque é parte movida e motora deste mundo - apenas pode ser fundante do mundo dos homens porque é categoria social. O trabalho é a categoria fundante não porque venha "antes" da sociedade (a rigor ela não pode existir fora do ser social, porque não é uma categoria da natureza), mas porque, na relação com a totalidade social, é o local por excelência da produção das necessidades e possibilidades que marcarão 0 desenvolvimento histórico do gênero humano (LESSA, 2007, p. 27).

\footnotetext{
${ }^{3}$ Para Lukács (2013, p. 46), "todo salto implica uma mudança qualitativa e estrutural do ser [...]. A essência do salto é constituída por essa ruptura com a continuidade normal do desenvolvimento e não pelo nascimento [...] da nova forma de ser". Engels (1952) também refletiu sobre o fenômeno do salto ontológico a partir de sua compreensão de que o trabalho foi a mediação que permitiu a transformação do macaco em homem. Para este autor o trabalho é, também, a condição fundamental de toda existência humana.
} 
Ocorre que, sob o capitalismo, sistema sociometabólico do capital (MÉSZÁROS, 2011), o trabalho se torna alienado, na medida em que o produto desta atividade não pertence mais ao sujeito da produção, mas ao capitalista, para quem o trabalhador vende sua força de trabalho em troca de um salário.

Portanto, o trabalho como atividade do homem voltada para a satisfação de suas necessidades, atividade criadora e criativa, torna-se, no modo de produção capitalista, um trabalho forçado, sofrido, fatigado e angustiante, de modo que apenas fora do trabalho é que o trabalhador se sente livre (MARX, 2008b).

Marx, em seus Manuscritos Econômico-Filosóficos (2008b), analisa quatro aspectos da alienação do trabalho. Em primeiro lugar, a alienação do produto do trabalho. Esse aspecto diz respeito à relação de estranhamento entre o trabalhador e o resultado do seu trabalho, uma vez que este possui uma existência exterior ao homem, aparecendo como independente dele e estranha a ele. Isso demonstra, nada mais, nada menos, que o objeto produzido pelo trabalhador, ou seja, o produto do seu trabalho, se Ihe apresenta como um ser estranho, independente de si. Entretanto, o produto resultante do trabalho não passa de trabalho objetivado.

Em segundo lugar, Marx analisa a alienação do processo de produção, denominada de auto-alienação. Ora, se o produto do trabalho da atividade do homem the é estranho, o próprio processo de produção é alienação, pois o produto não é outra coisa além do resumo da atividade, daquilo que se produz. Segundo o autor (2008b, p. 83) a vida é senão atividade; assim sendo, o processo de produção na sociedade capitalista aliena o homem de sua própria atividade humana, como atividade que acaba por não lhe pertencer, atividade como infortúnio, força como inoperância, "a energia espiritual e física própria do trabalhador, a sua vida pessoal (...) como uma atividade voltada contra ele mesmo, independente dele (...)". É a própria alienação de si.

Em terceiro lugar, a alienação da vida genérica. O homem é um ser genérico, universal e livre, que vive dos frutos da natureza. Esta, desse modo, constitui-se parte integrante do homem por ser seu meio de vida assim como instrumento de sua atividade vital; "a natureza é seu corpo, com o qual ele [o homem] tem de ficar num processo contínuo para não morrer" (MARX, 2008b, p. 84). O trabalho alienado, por sua vez, aliena a natureza do homem e aliena o homem de si mesmo. Transforma sua vida genérica em vida individual. "O trabalho, atividade vital, a vida produtiva 
mesma aparece ao homem apenas como um meio para a satisfação de uma carência, a necessidade de manutenção da existência física" (IDEM, IBIDEM). A vida resume-se a um meio imediato de sobrevivência, de subsistência imediata de vida.

Por fim, Marx (2008b, p. 86) analisa a alienação do homem em relação aos outros homens, trazendo o seguinte questionamento: "Se o produto do trabalho me é estranho, [se ele] defronta-se comigo como poder estranho, a quem ele pertence então? Se minha própria atividade não me pertence, é uma atividade estranha, forçada, a quem ela pertence então?". Assim, o autor conclui que esse outro ser a quem pertence o trabalho e o produto do trabalho só pode ser o próprio homem. Assim, a alienação do homem consigo mesmo e com a natureza também se expressa em sua relação com seus semelhantes.

Nesse sentido, na sociabilidade capitalista, todas as funções reprodutivas sociais, inclusive o trabalho, são subordinadas ao capital, que, de acordo com Mészáros (2011), não se constitui em uma entidade natural, nem tampouco uma estrutura que se possa racionalmente controlar, mas, constitui-se em um sistema sociometabólico incontrolável.

O sistema sociometabólico do capital é o primeiro na história a se constituir "como totalizador, irrecusável e irresistível" (MÉSZÁROS, 2011, p. 97), apresentando-se sobre um caráter expansionista, globalizante e destrutivo. Não havendo limites para sua expansão, esse sistema é, portanto, incontrolável, uma vez que se constitui na estrutura totalizadora mais poderosa que se formou no decorrer da história, a ponto de sujeitar tudo, inclusive os seres humanos, ao seu controle. Desse modo, esse sistema possui uma dinamicidade que supera a dinâmica dos anteriores sistemas de controle metabólico juntos. Para isso, o preço que se paga é a total perda da incapacidade de tomada de decisão, e não apenas do trabalhador, mas, inclusive, dos capitalistas mais ricos, que ou se submetem aos imperativos do sistema, ou perdem seus negócios. Assim, pode-se perceber que o sistema sociometabólico do capital não faz distinção de quem ou do que vai manipular, sujeitar e controlar. Aquele ou aquilo que não se sujeita a esse sistema perece, daí, portanto, seu caráter totalizador, irrecusável e irresistível, como qualificou Mészáros.

Para o mesmo autor (2011) não se pode imaginar outro sistema de controle mais absorvente e totalitário que o sistema sociometabólico do capital. Segundo ele,

O capital em si não passa de um modo e um meio dinâmico de mediação reprodutiva, devorador e dominador, articulado como um 
conjunto historicamente específico de estruturas e suas práticas sociais institucionalmente incrustadas e protegidas. É um sistema claramente identificável de mediações que, na forma adequadamente desenvolvida, subordina rigorosamente todas as funções de reprodução social - das relações de gênero e família até a produção material e a criação das obras de arte - à exigência absoluta de sua própria expansão, ou seja: de sua própria expansão constante e de sua reprodução expandida como sistema de mediação sociometabólico (MÉSZÁROS, 2011, p. 188).

Para se legitimar o sistema sociometabólico do capital apoia-se no tripé: trabalho alienado, capital e Estado, sendo, contudo, impossível superar o capital sem destruir essas três dimensões, que se encontram interligadas uma a outra. "Sendo assim, nem o capital, nem o trabalho, nem sequer o Estado podem ser simplesmente abolidos, mesmo pela mais radical intervenção jurídica" (MÉSZÁROS, 2011, p. 600). Destarte,

Devido à inseparabilidade das três dimensões do sistema do capital plenamente articulado - capital, trabalho e Estado -, é inconcebível emancipar o trabalho sem simultaneamente superar o capital e o Estado. Pois, paradoxalmente, o pilar material fundamental de suporte do capital não é o Estado, mas o trabalho em sua contínua dependência estrutural do capital (IDEM, IBIDEM, p. 601).

O Estado, por conseguinte, é uma estrutura jurídica extremamente importante para sustentar, legitimar e proteger o sistema sociometabólico do capital, alinhando sua estrutura reguladora com a dinâmica desse sistema. Entretanto, o principal pilar do sistema é o trabalho.

Marx (2004), ao analisar o trabalhado sob o domínio do capital, entende que este não é algo material, mas uma relação social de produção relacionada a uma dada formação social histórica corporificada em uma coisa material. É o conjunto dos meios de produção convertido em capital, a partir da apropriação por determinada parte da sociedade dos produtos e das condições do exercício da força de trabalho. É uma relação social que tem como base o trabalho assalariado. Assim, tanto o capital necessita do trabalho assalariado quanto este só existe em relação com aquele. Deste modo, "um se expressa no outro, um recria ou outro, um nega o outro" (IAMAMOTO, 2014, p. 37).

Marx (2008b) afirma ser o capital trabalho armazenado, fruto da apropriação privada do trabalho alheio, possuindo o poder de governar o trabalho e seus resultados. O capitalista tem o poder de se apropriar do trabalho alheio por ser ele 
proprietário do capital e não por suas propriedades humanas ou pessoais. O capital possui duas características que lhe são particulares: a mercadoria e a mais-valia.

$\mathrm{Na}$ sociedade capitalista, o objetivo do trabalho não é mais a produção de valores de uso que satisfaçam às necessidades humanas, mas de valores de troca para o capitalista e, sobretudo, de mais-valia. A produção de valor-de-uso é movida pelo interesse no valor-de-troca, voltado para a venda, ou seja, para a mercadoria. Esta se constitui a base da sociedade capitalista. Segundo Marx (2004, p. 57), a mercadoria é um objeto externo, algo que satisfaz necessidades humanas seja "qual for a sua natureza, a origem delas, provenham do estômago ou da fantasia". O autor, na citação abaixo, analisa detalhadamente as condições em que se dá o processo de produção da mercadoria:

Na produção de mercadorias, nosso capitalista não é movido por puro amor aos valores-de-uso. Produz valores-de-uso apenas por serem e enquanto forem substrato material, detentores de valor-detroca. Tem dois objetivos. Primeiro, quer produzir um valor-de-uso que tenha um valor-de-troca, um artigo destinado à venda, uma mercadoria. E segundo, quer produzir uma mercadoria de valor mais elevado que o valor conjunto das mercadorias necessárias para produzi-las, isto é, a soma dos valores dos meios de produção e força de trabalho, pelos quais antecipou um bom dinheiro no mercado. Além de um valor-de-uso, quer produzir mercadorias; além de valor-de-uso, valor, e não só valor, mas também valor excedente (mais-valia) (MARX, 2004, p. 220).

No capitalismo, ao emergir o trabalho livre ${ }^{4}$, o próprio trabalhador se torna uma mercadoria, uma vez que necessita vender sua força de trabalho para sobreviver. Quanto mais o trabalhador produz riqueza para o capitalista, mais miserável se torna; quanto maior quantidade de bens produz, torna-se uma mercadoria tanto quanto barata (MARX, 2008b).

O objetivo da produção de mercadoria é criar um valor excedente, gerar maisvalia. Esta se constitui na principal finalidade, sendo o meio determinante da produção, com o objetivo de diminuição do custo no processo produtivo. Portanto, a

\footnotetext{
${ }^{4} \mathrm{O}$ trabalho livre emerge a partir da sociabilidade capitalista. $\mathrm{O}$ trabalhador livre é aquele que necessita vender sua força de trabalho para sobreviver, dependendo da demanda por força de trabalho pelos empresários capitalistas. Segundo Marx (apud IAMAMOTO, 2001, p. 16) "Com respeito às condições econômicas é mera capacidade de trabalho e por isso, dotado de necessidades vitais. É um necessitado em todos os sentidos, visto não dispor das condições objetivas para a realização de sua capacidade de trabalho. Quando o capitalista não necessita do sobretrabalho do indivíduo ele não pode realizar o trabalho necessário, produzir seus meios de subsistência. Quando não pode obtê-los por meio do intercâmbio mercantil obterá por meio de esmolas que sobrem para ele da renda de todas as classes".
} 
produção capitalista não é apenas a produção de mercadorias, mas é, sobretudo, a produção de mais-valia, uma vez que o operário não produz para si mesmo, mas para o capital. Marx (2004) analisou dois tipos de mais-valia, a absoluta e a relativa:

Chamo de mais-valia absoluta a produzida pelo prolongamento do dia de trabalho, e de mais valia-relativa a decorrente da contração do tempo de trabalho necessário e da correspondente alteração na relação quantitativa entre ambas as partes componentes da jornada de trabalho (MARX, 2004, p. 366).

Portanto, a mais-valia não é, senão, valor excedente gerado pela força de trabalho. Assim, não é suficiente para o capitalista que o trabalhador apenas produza, mas que produza mais-valia. Para Marx (2004) só é produtivo o trabalhador que produz mais-valor, que contribui para a valorização do capital. A mais-valiaabsoluta se dá a partir do prolongamento da jornada de trabalho, além da necessária para a produção dos artigos, e a mais-valia-relativa, por sua vez, pela abreviação do tempo de trabalho socialmente necessário, o que contribui para a formação de uma população que passa a ser supérflua para o capital.

\section{A CRIAÇÃO DE UMA POPULAÇÃO SUPÉRFLUA PARA O CAPITAL}

Como forma de garantia de sua reprodução o capital procura, por um lado, adiantar dinheiro através da incorporação da força viva de trabalho ao processo de produção, com intensa extração de mais-valia absoluta. Com a mais-valia-relativa, por outro lado, o capital rejeita parte significativa dessa mesma força de trabalho. Assim, a partir dos lucros com a produtividade, proveniente da exploração da força de trabalho sob a forma de mais-valia, o capitalista incorpora no processo de produção os avanços técnicos e científicos, contribuindo para que os trabalhadores produzam uma maior quantidade de produtos em um menor tempo. Em consequência disso,

Reduz-se o tempo de trabalho socialmente necessário à produção de mercadorias [...] ampliando simultaneamente o tempo de trabalho excedente ou mais-valia. [...] Reduz-se relativamente o capital variável - empregado na força de trabalho- e aumenta-se o capital constante, empregado nos meios materiais de produção. A incorporação das conquistas da ciência no processo de produção na sua globalidade - ela mesma uma força produtiva por excelência contribui para acelerar a produtividade do trabalho e a rotação do 
capital, permitindo uma ampliação das taxas de lucratividade [...]. (IAMAMOTO, 2001, p. 14).

Portanto, com o avanço da técnica e da ciência na produção ao invés de se proporcionar tempo livre para os trabalhadores, o que se tem é a intensificação de sua exploração. Ou seja, com a redução do tempo de trabalho socialmente necessário o capital busca intensificar a extração de mais-valia daqueles que mantêm nos postos de trabalho, lançando muitos outros ao ócio forçado (SANTOS, 2012).

A partir dessa lógica, forma-se uma quantidade de trabalhadores supérfluos para o capital, mas que o subsidia em suas necessidades, como, por exemplo, favorecendo a concorrência entre os trabalhadores, interferindo, inclusive, na regulação dos salários. Tais características são expressões da própria lei geral da acumulação capitalista, isto é: “(...) apesar de criar e recriar a necessidade de integrar a maior quantidade de trabalhadores ativos para ocupar os postos de trabalho, gerando mais sobre trabalho, o capital, contraditoriamente, realiza um movimento oposto" (MARANHÃO, 2010, p. 44). De acordo com lamamoto (2001, p. 15),

Cresce (...) uma superpopulação relativa para esse padrão de desenvolvimento (...) os supérfluos para o capital, acirrando a concorrência entre os trabalhadores - a oferta e a procura, com evidente interferência na regulação de salários (...). Dentre essa superpopulação relativa - que à época da revolução industrial inglesa era qualificada de "exército industrial de reserva" encontram-se os segmentos intermitentes, sujeitos às oscilações cíclicas e eventuais de absorção e repulsa do trabalho nos centros industriais; a superpopulação latente na agricultura, fruto da redução de demanda de força de trabalho decorrente do seu processo de industrialização, não acompanhada de igual capacidade de absorção dos trabalhadores nos polos urbano-industriais. Inclui-se também aquela parcela estagnada de trabalhadores ativos com ocupações irregulares e eventuais: os precarizados, temporários, com "máximo de tempo de serviço e mínimo de salário", sobrevivendo abaixo do nível médio da classe trabalhadora (IAMAMOTO, 2001, p. 15).

Deste modo, ao mesmo tempo em que se tem um desenvolvimento no modo de produção, tem-se um retrocesso para a condição do trabalhador. A lei da acumulação capitalista incide de forma voraz sobre aqueles que detêm unicamente sua força de trabalho para sobreviver, criando uma reserva de trabalhadores disponíveis ao capital, mas que pode ou ser absorvida em momentos expansivos, ou expulsa em períodos de crise, na medida em que se tenha acumulação. 
Fica claro, portanto, que tal lei cria uma condição de extrema exploração e precarização para os trabalhadores, provocando o desemprego estrutural, uma vez que 0 trabalho desempenhado pelas máquinas substitui grande quantidade de trabalhadores que não conseguirão mais acessar postos de trabalho. Dessa forma, essa situação acirra as desigualdades sociais e o crescimento do pauperismo ${ }^{5}$ gerando um acúmulo da miséria atinente à acumulação capitalista.

$\mathrm{Na}$ contemporaneidade tem-se ainda mais o aumento do desemprego estrutural e, consequentemente, da quantidade de pessoas destituídas de trabalho, tendo em vista a reestruturação do capital ${ }^{6}$, marcada pelo avanço técnico científico baseado na incorporação de tecnologias como a automação e a microeletrônica ao processo de produção. Aliada a esse avanço da robótica, a nova forma de acumulação que se impõe, que é a chamada acumulação flexível, amplia o processo de substituição da força de trabalho vivo pelo trabalho incorporado aos meios materiais de produção, favorecendo, assim, o processo de precarização, o rebaixamento do valor da força de trabalho e o aumento do desemprego.

De acordo com pesquisa recente divulgada pelo Instituto Brasileiro de Geografia e Estatística (IBGE), o desemprego no Brasil corresponde a 13,7\%, chegando a atingir 14,2 milhões de brasileiros ${ }^{7}$. Segundo a mesma pesquisa, o desemprego no País mais que dobrou nos últimos três anos. Portanto, se o desemprego é próprio do capital, este se utiliza ainda mais da força de trabalho para explorá-la a partir da intensificação da precarização e dos subempregos. Antunes (2001) mostra que os trabalhadores são usados pelo capital como se fossem uma seringa descartável.

Bauman é outro autor que traz uma análise relevante sobre o desemprego na contemporaneidade. Em sua obra intitulada "Vidas Desperdiçadas" (2005), o autor analisa que a modernização produz inevitavelmente o "refugo" ou seres humanos

\footnotetext{
${ }^{5}$ Pauperismo constitui-se na "expressão das contradições inerentes ao capitalismo que, ao constituir o trabalho vivo como única fonte de valor e, ao mesmo tempo, reduzi-lo progressivamente em decorrência da elevação da composição orgânica do capital - o que implica o predomínio do trabalho morto sobre 0 vivo -, promove a expansão do exército industrial de reserva ou superpopulação relativa em larga escala". (BHERIN G e BOSCHETTI, 2011, p. 52-53).

${ }^{6}$ A reestruturação produtiva constitui-se numa das estratégias de restauração do capital diante da crise estrutural que se inicia nos anos 1970. Baseada na chamada acumulação flexível, tem-se um processo de flexibilização não apenas o modelo de produção, mas implica diretamente nos processos de trabalho, nas suas formas de gestão, assim como nos direitos dos trabalhadores e na sua na organização política (ANTUNES, 1995).

7 Informações extraídas da página: http://g1.globo.com/economia/noticia/desemprego-fica-em-137-no1-trimestre-de-2017.ghtml. 18/07/2017
} 
refugados, os "excessivos", "redundantes". Bauman constata que um dos diagnósticos mais comuns vivenciados pela geração $X$, pessoas nascidas na década de 1970, é o desemprego. Se as pessoas que vivenciaram o período de desenvolvimento industrial que estavam sem emprego, o chamado exército industrial de reserva, teriam o destino do retorno ao trabalho, para o refugo o destino é o depósito de lixo. Bauman (2005, p. 20) assim define a população redundante:

Ser "redundante" significa ser extranumerário, desnecessário, sem uso (...). Os outros não necessitam de você. Podem passar muito bem, e até melhor, sem você. Não há uma razão autoevidente para você existir nem qualquer justificativa óbvia para que você reivindique o direito à existência. Ser declarado redundante significa ter sido dispensado pelo fato de ser dispensável - tal como a garrafa de plástico vazia e não retornável, ou a seringa usada, uma mercadoria desprovida de atração e de compradores, ou um produto abaixo do padrão, ou o machado, sem utilidade, retirado da linha de montagem pelos inspetores de qualidade. "Redundância" compartilha o espaço semântico de "rejeitos", "dejetos", "restos", "lixo" - com refugo (grifos do autor).

O autor acrescenta que os redundantes, inclusive, são considerados um problema financeiro, uma vez que são incapazes de sobreviver por conta própria. A análise do autor, ao considerar que o fim dos redundantes é o depósito de dejetos, embora pareça chocante, constitui-se numa realidade lamentável, uma vez que, de fato, muitas pessoas não serão mais (re) inseridas no mercado de trabalho.

\section{CONCLUSÃO}

Esse artigo buscou fazer uma reflexão sobre a lei geral da acumulação capitalista, que cria uma população supérflua para o capital, favorecendo, com isso, o desenvolvimento e o crescimento do pauperismo e o fenômeno do desemprego estrutural, pois, na medida em que o capital incorpora máquinas no processo produtivo, lança considerável número de trabalhadores ao ócio forçado não remunerado.

A partir do que foi exposto tornou-se visível que o mundo do trabalho hoje é marcado pelo desemprego estrutural, pela precarização do trabalho, pela diminuição dos direitos trabalhistas, dentre outras condições perversas para a classe trabalhadora. Assim, homens e mulheres, trabalhadores e trabalhadoras "livres", que não dispõem de outra coisa para manter sua sobrevivência a não ser vendendo sua 
força de trabalho em troca de salário, veem-se a cada dia privados até dessa condição, passando a ser tratados como "refugo" (BAUMAN, 2005).

Antunes, em sua obra "Os Sentidos do Trabalho" (2001, p. 175), faz a seguinte afirmação: "uma vida cheia de sentido fora do trabalho supõe uma vida dotada de sentido dentro do trabalho". Essas palavras tornam-se impactantes quando se pensa nas pessoas que estão vivenciando o emprego precário, o desemprego e, principalmente, os que nunca tiveram e/ou nunca terão participação no mercado de trabalho formal. Vale ressaltar, como bem fez Netto e Braz (2006), que o desemprego não é consequente do desenvolvimento das forças produtivas, mas, sim, do desenvolvimento das forças produtivas sob o domínio capitalista

\section{REFERÊNCIAS}

ANTUNES, Os Sentidos do Trabalho: ensaios sobre a afirmação e a negação do trabalho. 6. ed. São Paulo: Boitempo Editorial, 2001.

Adeus ao trabalho? Ensaio sobre as metamorfoses do e a centralidade do mundo do trabalho. São Paulo; Cortez; Campinas, SP: Editora da Universidade Estadual de Campinas, 1995.

ANTUNES, Ricardo; ALVES, Giovanni. As mutações no mundo do trabalho na era da mundialização do capital. Educação \& Sociedade. Campinas, vol. 25, n. 87, p. 335-351, maio / ago., 2004.

BAUMAN, Zygmunt, 1925. Vidas desperdiçadas. Tradução de Carlos Alberto Medeiros. Rio de Janeiro: Zahar, 2005.

BEHRING, Elaine Rossetti e BOSCHETTI, Ivanete. Política Social: fundamento e história. 9ª ed. São Paulo: Cortez, 2011. (Biblioteca Básica de Serviço Social, v. 2).

ENGELS, Friedrich. 1876. Sobre o papel do trabalho na transformação do macaco em homem. Edição soviética de 1952, de acordo com o manuscrito, em alemão. Traduzido do espanhol. Disponível em: http://www.marxists.org/portugues/marx/1876/mes/macaco.htm. Acesso em: $18 / 07 / 2017$ 
IAMAMOTO, Marilda Villela e CARVALHO, Raul de. Relações sociais e serviço social no Brasil: esboço de uma interpretação histórico-metodológica. 41ª . ed. São Paulo: Cortez, 2014.

A questão social no capitalismo. In: Associação Brasileira de Ensino e Pesquisa em Serviço Social. Revista. Ano 2, n.3 (jan/jul.2001). Brasília: ABEPSS, Grafline, 2001.

LESSA, Sérgio. Mundo dos Homens: trabalho e ser social. $1^{\circ}$ ed. São Paulo: Boitempo Editoral, 2002.

Serviço social e trabalho: porque o serviço social não é trabalho. Maceió: EDUFAL, 2007

LUKÁCS, György. Para uma ontologia do ser social. Tradução de Néllio Schneider, Ivo Tonet, Ronaldo Vielml Fortes. $1^{\underline{a}}$ ed. São Paulo: Boitempo, 2013.

LUKÁCS, György. As bases ontológicas do pensamento e da atividade do homem. Disponível em: http://www.giovannialves.org/Bases_Luk\%E1cs.pdf. Acesso em 18/07/2017

MARANHÃO, Cézar Henrique. Capital e superpopulação relativa: em busca das raízes contemporâneas do desemprego e do pauperismo. In: BEHRING, Elaine Rossetti e ALMEIDA, Maria Helena Tenório (orgs.). Trabalho e seguridade social: percursos e dilemas. 2ª ed. São Paulo: Cortez; Rio de Janeiro: FSS / UERJ, 2010.

MARX, Karl. O capital - crítica da economia política. Livro 3. Volume6. Tradução de Reginaldo Sant Anna. Rio de Janeiro: Civilização Brasileira, 2008a.

O capital: crítica da economia política: livro 1. Tradução de Reginaldo Sant'Anna. 22a ed. - Rio de Janeiro: Civilização Brasileira, 2004.

Manuscritos econômicos-filosóficos. Boitempo editorial, $2^{\mathrm{a}}$ reimpressão: março de 2008 b. 
MÉSZÁROS, István. Para além do capital: rumo a uma teoria da transição. Tradução de Paulo Cézar Castanheiras, Sérgio Lessa. $1^{\underline{a}}$ ed. revista. São Paulo: Boitempo, 2011.

NETTO, José Paulo. Economia política: uma introdução crítica. José Paulo Netto e Marcelo Braz. - São Paulo: Cortez, 2006.

SANTOS, Josiane Soares. "Questão social”: particularidades no Brasil. São Paulo: Cortez, 2012. (Coleção biblioteca básica de serviço social; v. 6). 